RASĀYAN J. Chem.

Vol. 13 | No. 3 |1531-1536| July - September | 2020 ISSN: 0974-1496 | e-ISSN: 0976-0083 | CODEN: RJCABP

\title{
CHARACTERIZATION OF CHOLESTEROL DEGRADING Micrococcus indicus E2 ISOLATED FROM OIL PROCESSING WASTE
}

\author{
A. L. Jangala* and K. Pulipati \\ Department of Chemical Engineering, Andhra University, Visakhapatnam-530003, \\ (Andhra Pradesh) India. \\ *E-mail: ashalatha.jangala@gmail.com
}

\begin{abstract}
An extracellular cholesterol oxidase producing bacteria was isolated from soil samples collected at the oil mill region of Visakhapatnam, Andhra Pradesh, India. Altogether 88 isolates were observed and screened for extracellular cholesterol oxidase enzyme activity. Of the 88 isolates, 9 were found to be potential cholesterol oxidase producers. Among the 9 isolates, the bacterial isolate E2 was the most efficient in enzyme production and was selected for further studies. The selected strain was identified as a Micrococcus species based on biochemical tests. Based on molecular characterization, the strain has been closely related to Micrococcus indicus strain AK39766 (100\% similarity) and designated as Micrococcus indicus E2.
\end{abstract}

Keywords: Cholesterol oxidase, Micrococcus indicus E2, Molecular Characterization, Oil Mill Region, Soil Samples.

(C) RASĀYAN. All rights reserved

\section{INTRODUCTION}

Some microorganisms present in the soil utilize cholesterol for their growth and survival. They produce an enzyme known as cholesterol oxidase (COX), a flavoenzyme of oxidoreductase family. COX, catalyzes cholesterol catabolism and convert it into 4-cholestene-3-one. ${ }^{1}$

COX is produced by a variety of microorganisms that are found in varied environments and conditions. COX has been found in several microbial sources, including members of the genera Arthrobacter ${ }^{2}$, Brevibacterium $^{3}$, Bordetella $^{4}$, Bacillus $^{5}$, Chromobacterium $^{6}$, Mycobacterium $^{7}$, Nocardia $^{8}$, Pseudomonas $^{9}$, Rhodococcus ${ }^{10}$ and Streptomyces. ${ }^{11}$ This enzyme is secreted in intracellular, extracellular and membranebound forms. Microbial COX has gained significant attention due to their potential industrial and clinical applications. For instance, COX is mainly used in the detection of serum cholesterol in humans, agriculture, and a precursor for the production of pharmaceutical steroids. ${ }^{12-14}$ More importantly, COX can be used in dietary cholesterol degradation which is considered as an effective strategy to treat atherosclerosis. In addition to this, transgenic plants expressing COX has been generated, to protect the crops from fungal attacks ${ }^{15}$. As COX is known to have multiple applications, isolation and screening of novel bacterial strains producing an extracellular form of COX have significant importance. Hence, this study was intended to isolate and characterize the cholesterol degrading bacteria from the soils dumped with oil processing waste.

\section{Materials and Methods}

\section{EXPERIMENTAL}

Soil samples containing waste such as hospital waste, slaughterhouse waste, restaurant waste, dairy waste, oil mill waste were collected from different areas of the Visakhapatnam region, Andhra Pradesh, India. Approximately $10 \mathrm{~g}$ of soil sample was collected in ziploc covers by using a clean, dry and sterile spatula. These soil samples were then processed for subsequent analyses.

\section{Isolation of Microorganisms}

The soil sample was serially diluted as follows; $1 \%$ soil from each sample was used for serial dilution and placed in a shaker for $30 \mathrm{~min}$. The suspension was then serially diluted up to 10 levels. $0.1 \mathrm{ml}$ of solution Rasayan J. Chem., 13(3), 1531-1536(2020) http://dx.doi.org/10.31788/ RJC.2020.1335665

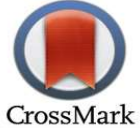


RASĀYAN $J$. Chem.

Vol. 13 | No. 3 |1531-1536| July - September | 2020

from the $10^{-4}$ dilution was inoculated onto the mineral agar screening medium, consisting of $0.1 \%$ cholesterol, $0.25 \mathrm{~g} \mathrm{~K}_{2} \mathrm{HPO}_{4}, 0.05 \mathrm{~g} \mathrm{NaCl}, 17 \mathrm{~g} \mathrm{NH}_{4} \mathrm{NO}_{3}, 0.25 \% \mathrm{MgSO}_{4} . \mathrm{H}_{2} \mathrm{O}, 0.001 \mathrm{~g} \mathrm{FeSO}_{4} .7 \mathrm{H}_{2} \mathrm{O}, 1.5 \%$ agar and Tween $80(0.5 \mathrm{ml})$, with $\mathrm{pH} 7$, followed by incubation at $37^{\circ} \mathrm{C}$ for 3 to 4 days. The abscission colonies observed after 3 days were sub-cultured in enriched mineral agar medium containing cholesterol as well as yeast extract $(0.5 \% \mathrm{w} / \mathrm{v})$ and incubated for the next 4 days at $37^{\circ} \mathrm{C}^{16}$. Then, prominent colonies developed were picked up and maintained on nutrient agar slants for further study.

\section{Screening of COX Producing Microorganisms}

COX producing microorganisms were screened by using suitable indicator plates. The isolates were inoculated and incubated on the indicator plates consisting of $0.1 \%$ cholesterol, $0.1 \%$ Triton $\mathrm{X}-100$, $0.01 \%$ o-dianisidine, $1.5 \%$ agar and $1000 \mathrm{U} / 1$ horseradish peroxidase (HRP), at $30^{\circ} \mathrm{C}$ for 3 days. Hydrogen peroxide $\left(\mathrm{H}_{2} \mathrm{O}_{2}\right)$ released during the enzymatic reaction mediated by COX, reacts with the odianisidine present in the medium and forms an azo compound that changes the medium color into deep brown color. ${ }^{17,18}$

\section{Quantitative Determination of COX Activity}

Supernatants from the culture broths were collected by centrifuging at $10,000 \mathrm{rpm}$ for $20 \mathrm{~min}$ at $4^{\circ} \mathrm{C}$ after 3 days of cultivation and used as extracellular COX solution. ${ }^{19}$ Extracellular COX enzyme activity was analyzed as per the protocol described by Inouye et al. ${ }^{20}$ The reaction mixture consisted of $100 \mu \mathrm{l}$ of extracellular COX solution, $400 \mu \mathrm{l}$ of $125 \mathrm{mM}$ Tris- $\mathrm{HCl}$ buffer of $\mathrm{pH} 7.5$. This enzyme and buffer solution mixture was placed in a water bath at $37^{\circ} \mathrm{C}$ during the incubation period $(3 \mathrm{~min})$. To this mixture, $25 \mu \mathrm{l}$ of $12 \mathrm{mM}$ of cholesterol in isopropyl alcohol solution was added and the reaction was carried out for $30 \mathrm{~min}$. The reaction was stopped by adding $2.5 \mathrm{ml}$ of absolute ethanol and the amount of 4-cholesten3-one formed was measured at $240 \mathrm{~nm}$. $25 \mu \mathrm{l}$ of isopropyl alcohol was used instead of cholesterol to prepare the reaction blanks. One unit of activity was defined as the amount of enzyme that forms 1.0 $\mu \mathrm{mol}$ of 4-cholesten-3-one at $37^{\circ} \mathrm{C}$ under the assay conditions.

\section{Identification of Isolate}

The bacterial isolate was identified according to Bergey's manual of determinative bacteriology. Biochemical and molecular characterization of the bacterial isolate was conducted as per the established standard methods. 16s rDNA sequencing was done for the final evaluation of isolated bacteria and the sequence was amplified by using Universal primers forward and reverse primers, 27F 5'AGAGTTTGATCMTGGCTCAG3' and 1492R 5'TACGGYTACCTTGTTACGACTT3'. The obtained sequence was then compared with the other NCBI databases. Further to this, multiple sequence alignment was carried out by CLUSTAL W 1.8 software to construct a phylogenetic tree. ${ }^{21}$ The sequence of the isolate was deposited and received the accession number from GenBank.

\section{RESULTS AND DISCUSSION}

Soil samples collected from five different locations of Visakhapatnam city were screened for isolation of bacteria. Altogether 88 morphologically different bacterial colonies being capable of growing on cholesterol-containing mineral agar medium were isolated. Each of the 88 isolates was screened for COX production. Of the 88 isolates, nine bacterial isolates A11, B1, B12, B13, C7, D1, D12, E1 and E2 showed activity on the cholesterol oxidase indicator plate. The COX production was determined by a spectrophotometer at $240 \mathrm{~nm}$ and isolate E2 showed high enzyme activity in comparison to the other isolates (Fig.-1). The extracellular COX activity of isolate E2 was found to be $0.57 \mathrm{U} / \mathrm{ml}$. On the other hand, Wang et al. reported extracellular COX production of Rhodococcus $s p$. $\mathrm{R}_{14-2}$ is about $1.5 \mathrm{U} / \mathrm{ml}$, whereas COX production from Staphylococcus and Micrococcus $s p$. was reported as $0.15 \mathrm{U} / \mathrm{ml}$, after the purification process. ${ }^{22,23}$

The results of Phenotypic and biochemical characteristics of the top four isolates are shown in Table-1. Microscopic observation shows that isolate E2 cells are Gram-positive, round-shaped typically $0.5 \mu \mathrm{m}$ in diameter, $2 \mu \mathrm{m}$ in length and non-motile (Fig.-2). The partial sequence of 16s rDNA ( $900 \mathrm{bp}$ ) was 
RASĀYAN J. Chem.

Vol. 13 | No. 3 |1531-1536| July - September | 2020

shown in Table-2 and the sequence similarity between the isolate E2 and its nearest neighbor in the Micrococcus genus, Micrococcus indicus strain AK39766 was 100\% (Table-3 and Fig.-3).

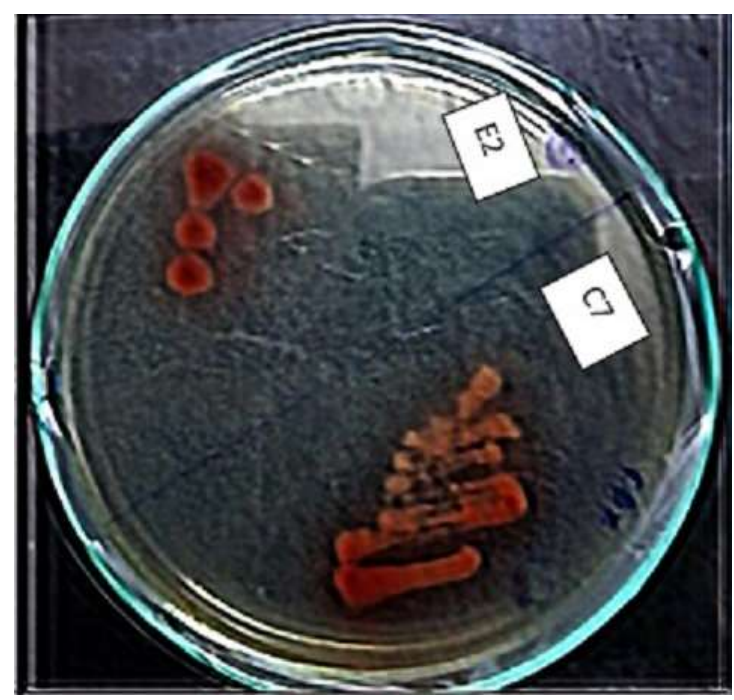

Fig.-1: Growth of isolate E2 on Cholesterol Oxidase Indicator Plate

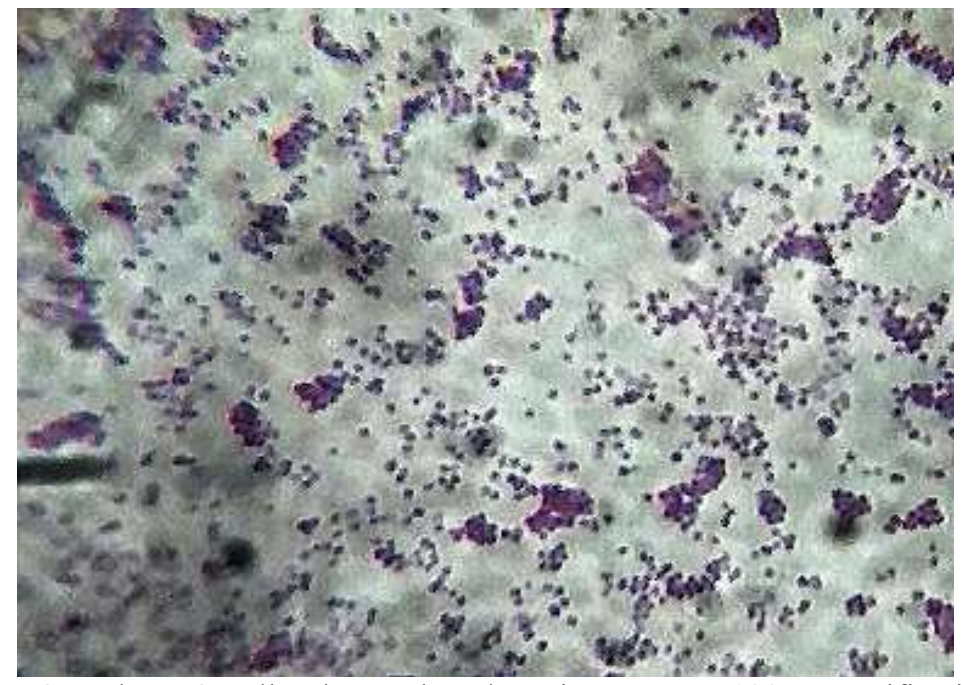

Fig.-2: Isolate E2 Cells Observed Under Microscope at 100x Magnification

The isolate E2 was identified as Micrococcus indicus based on the gene sequence analyses and other parameters employed. The nucleotide sequence of the16s rDNA of Micrococcus indicus E2 was submitted to GenBank (accession number MK569017).

Table-1: Phenotypic and Biochemical Characteristics of Top Four Isolates.

\begin{tabular}{c|c|c|c|c|c}
\hline S. No. & Cultural Characteristics & Isolate A11 & Isolate B1 & Isolate C7 & Isolate E2 \\
\hline 1 & Colony Color & White & Yellow & Yellow & Cream \\
\hline 2 & Colony Shape & Round & Round & Uneven & Round \\
\hline 3 & Grams Staining & + & - & + & + \\
\hline 4 & Citrate Utilization & + & + & - & - \\
\hline 5 & Nitrate Reduction & - & - & - & + \\
\hline 6 & MR & - & - & - & + \\
\hline 7 & VP & - & - & - & + \\
\hline
\end{tabular}


RASĀYAN J. Chem.

Vol. 13 | No. 3 |1531-1536| July - September | 2020

\begin{tabular}{c|c|c|c|c|c}
\hline 8 & Starch Hydrolysis & + & + & + & + \\
\hline 9 & Motility & + & - & - & - \\
\hline 10 & Catalase & + & + & - & + \\
\hline 11 & Salt Tolerance & - & - & - & + \\
\hline
\end{tabular}

Table-2: Partial Sequence of 16s rDNA of isolate E2.

CCTGCGCTTGACTCTGGGATAAGCCTGGGAAACTGGGTCTAATACCGGATAGGAACGTCC ACCGCATGGTGGTTGTTGGAAAGATTTATCGGTCATGGATGGACTCGCGGCCTATCAGCTT GTTGGTGAGGTAATGGCTCACCAAGGCGACGACGGGTAGCCGGCCTGAGAGGGTGACCG GCCACACTGGGACTGAGACACGGCCCAGACTCCTACGGGAGGCAGCAGTGGGGAATATT GCACAATGGGCGAAAGCCTGATGCAGCGACGCCGCGTGAGGGATGACGGCCTTCGGGTT GTAAACCTCTTTCAGTAGGGAAGAAGCGAAAGTGACGGTACCTGCAGAAGAAGCACCGG CTAACTACGTGCCAGCAGCCGCGGTAATACGTAGGGTGCGAGCGTTATCCGGAATTATTG GGCGTAAAGAGCTCGTAGGCGGTTTGTCGCGTCTGTCGTGAAACTCCGGGGCTTAACCCC GGATCTGCGGTGGGTACGGGCAGACTAGAGTGCAGTAGGGGAGACTGGAATTCCTGGTGT AGCGGTGGAATGCGCAGATATCAGGAGGAACACCGATGGCGAAGGCAGGTCTCTGGGCT GTAACTGACGCTGAGGAGCGAAAGCATGGGGAGCGAACAGGATTAGATACCCTGGTAGT CCATGCCGTAAACGTTGGGCACTAGGTGTGGGGACCATTCCACGGTTTCCGCGCCGCAGC TAACGCATTAAGTGCCCCGCCTGGGGAGTACGGCCGCAAGGCTAAAACTCAAAGGAATTG ACGGGGGCCCGCACAAGCGGCGGAGCATGCGGATTAATTCGATGCAACGCGAAGAACCT TACCAAGGCTTGACATGTTCTCGATCGCCGTAGAGATACGGTTTCCCCTTTGGGGCGGGAT CACAGGTGGTGCATGGTTGTCGTCAGCTCGTGTCGTGAGATGTTGGGTTAAGTCCCGCAAC GAGCGCAACCCTCGTTCCATGTTGCCAGCACGTAATGGTGGGGACTCATGGGAGACTGCC GGGGTCAACTCGGAGGAAGGTGGGGACGACGTCAAATCATCATGCCCCTTATGTCTTGGG CTTCACGCATGCTACAATGGCCGGTACAATGGGTTGCGATACTGTGAGGTGGAGCTAATC CCAAAAAGCCGGTCTCAGTTCGGATTGGGGTCTGCAACTCGACCCCATGAAGTCGGAGTC

Table-3: 16s rDNA Sequence Similarity Values between Micrococcus indicus and the Representatives of the genus Micrococcus.

\begin{tabular}{c|c|c|c|c|c}
\hline S. No. & Name & Strain & $\begin{array}{c}\text { Accession } \\
\text { numbers }\end{array}$ & Identities & Diff/Total nt \\
\hline 1 & Micrococcus indicus & AK39766 & HQ234347 & $\begin{array}{c}1231 / 1231 \\
(100 \%)\end{array}$ & $0 / 1231$ \\
\hline 2 & Micrococcus luteus & PS4 & MH778045 & $\begin{array}{c}1231 / 1229 \\
(99.83 \%)\end{array}$ & $2 / 1231$ \\
\hline 3 & Micrococcus indicus & B7 & EU169174 & $\begin{array}{c}1231 / 1229 \\
(99.83 \%)\end{array}$ & $2 / 1231$ \\
\hline 5 & Micrococcus indicus & IARI-CS-31 & JF343132 & $\begin{array}{c}1231 / 1229 \\
(99.83 \%)\end{array}$ & $2 / 1231$ \\
\hline 6 & Actinobacterium & C46 & AB330816 & $\begin{array}{c}1231 / 1228 \\
(99.75 \%)\end{array}$ & $3 / 1231$ \\
\hline 7 & $\begin{array}{c}\text { Micrococcus } \\
\text { aloeveras }\end{array}$ & SP-01 & KX082871 & $\begin{array}{c}1231 / 1228 \\
(99.75 \%)\end{array}$ & $3 / 1231$ \\
\hline
\end{tabular}

COX enzyme is observed to be having both industrial and commercial importance. Earlier studies have reported a wide spectrum of microorganisms, with an ability to produce COX enzyme. The preliminary work conducted through this present study suggests that Micrococcus indicus E2, isolated from oil processing waste, may stand as a possible source of extracellular COX production, which has both clinical and commercial value. Perhaps, this is the first report that suggests the production of COX 
RASĀYAN J. Chem.

Vol. 13 | No. 3 |1531-1536| July - September | 2020

enzyme by Micrococcus indicus E2 which was isolated from soil samples of the Visakhapatnam region, AP, India.

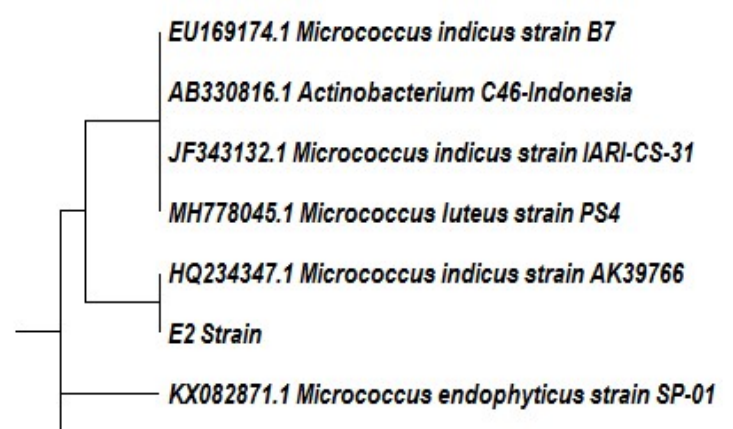

KX502917.1 Micrococcus aloeverae strain YIM 130916

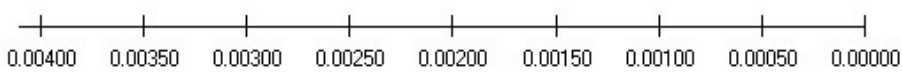

Fig.-3: Phylogenetic Tree of the isolate E2 based on 16S rDNA Sequence

\section{ACKNOWLEDGMENT}

We would like to thank the UGC (RGNF) for their financial assistance.

\section{REFERENCES}

1. J. Kreit and N.S. Sampson, FEBS Journal, 23, 6844(2009), DOI:10.1111/j.1742-4658.2009.07378.x

2. Y.R. Chen, H.H. Huang, Y.F. Cheng, T.Y. Tang and W.H. Liu, Enzyme and Microbial Technology, 4, 854(2006), DOI:10.1016/j.enzmictec.2006.01.018

3. K. Fujishiro, H. Uchida, K. Shimokawa, M. Nakano, F. Sano, T. Ohta, N. Kayahara, K. Aisaka and T. Uwajima, FEMS Microbiology Letters, 2, 243(2002), DOI:10.1111/j.1574-6968.2002.tb11397.x

4. Y. Lin, J. Fu and X. Song, Process Biochemistry, 9, 1563(2010), DOI:10.1016/j.procbio.2010.06.00

5. L. Kumari and S.S. Kanwar, Applied Biochemistry and Biotechnology, 2, 353(2016), DOI: $10.1007 / \mathrm{s} 12010-015-1877-7$

6. N. Doukyu, K. Shibata, H. Ogino and M. Sagermann, Applied Microbiology and Biotechnology, 1, 59(2008), DOI:10.1007/s00253-008-1526-y

7. A. Brzostek, B. Dziadek, A. Rumijowska-Galewicz, J. Pawelczyk and J. Dziadek, FEMS Microbiology Letters, 1, 106(2007), DOI:10.1111/j.1574-6968.2007.00865.x

8. M. Sojo, R. Bru, D. Lopez-Molina, F. Garcia-Carmona and J.C. Arguelles, Applied Microbiology and Biotechnology, 5, 583(1997), DOI:10.1007/s002530050977

9. N. Doukyu and S. Nihei, Journal of Bioscience and Bioengineering, 1, 24(2015), DOI: $10.1016 /$ j.jbiosc.2014.12.003

10. M.T. Yazdi, Z.T. Yazdi, G. Zarrini, Z. Sepehrizadeh, A. Ghasemian, Biotechnology, 4, 751(2008), DOI: 10.3923/biotech.2008.751.756

11. V. Praveen, A. Srivastava, C.K.M. Tripathi, Applied Biochemistry and Biotechnology, 5-6, 1414(2011), DOI: 10.1007/s12010-011-9360-6

12. S.K. Arya, M. Datta and B.D. Malhotra, Biosensors and Bioelectronics, 7, 1083(2008), DOI: $10.1016 /$ j.bios.2007.10.018

13. D. Noriyuki, Applied Microbiology and Biotechnology, 5, 825(2009), DOI:10.1007/s00253-0092059-8

14. S. Devi and S.S. Kanwar, Insights Enzyme Reseach, 1, (2017), DOI:10.21767/2573-4466.100005

15. L. Pollegioni, L. Piubelli, G. Molla, The FEBS Journal, 23, 6857(2009), DOI:10.1111/j.17424658.2009.07379.x

16. M.T. Yazdi, F. Malekzadeh, G.H. Zarrini, M.A. Faramarzi, N. Kamranpour and S.H. Khaleghparast, 
RASĀYAN J. Chem.

Vol. 13 | No. 3 |1531-1536| July - September | 2020

World Journal of Microbiology and Biotechnology, 7,731(2001), DOI:10.1023/a: 1012993532686

17. T. Nishiya, N. Harada, S.I. Teshima, M. Yamashita, I. Fujii, N. Hirayama and Y. Murooka, Protein Engineering, 3, 231(1997), DOI:10.1093/protein/10.3.231

18. O. Drzyzga, L.F. De Las Heras, V. Morales, J.N. Llorens and J. Perera, Applied Environmental Microbiology, 14, 4802(2011), DOI:10.1128/AEM.05149-11

19. J. Kreit, G. Lefebvre, A. Elhichami, P. Germain and M. Saghi, Lipids, 6, 458(1992), DOI: $10.1007 / \mathrm{BF} 02536389$

20. Y. Inouye, K. Taguchi, A. Fujii, K. Ishimaru, S. Nakamura and R. Nomi, Chemical and Pharmaceutical Bulletin, 3, 951(1982), DOI:10.1248/cpb.30.951

21. K. Tamura, G. Stecher, D. Peterson, A. Filipski and S. Kumar, Molecular Biology and Evolution, 12, 2725(2013), DOI: 10.1093/molbev/mst197

22. C. Wang, Y. Cao, B. Sun, B. Ji, M.R. Nout, J. Wang, and Y. Zhao, World Journal of Microbiology and Biotechnology, 10, 2149(2008), DOI:10.1007/s11274-008-9722-6

23. M. Engavale and M. Deshmukh, IOSR Journal of Pharmacy and Biological Sciences, 10, 109(2015), DOI: $10.9790 / 3008-1063109112$

[RJC-5665/2020] 